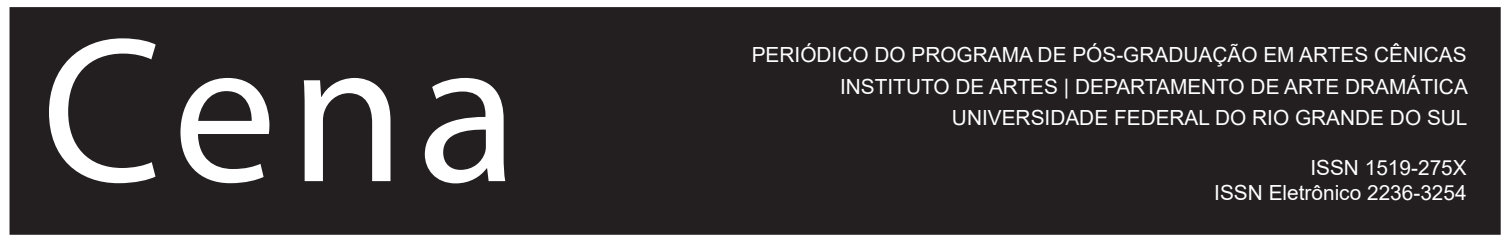

\title{
Pedagogias(s) das Artes Cênicas: Parcerias, colaborações em rede e possibilidades de existência
}

\author{
Vera Lúcia Bertoni dos Santos \\ Universidade Federal do Rio Grande do Sul - UFRGS/RS, Brasil \\ E-mail: bertonica@gmail.com \\ Josiane Gisela Franken Corrêa \\ Universidade Federal de Pelotas - UFPEL, Pelotas/RS, Brasil \\ E-mail: josianefranken@gmail.com \\ Clóvis Dias Massa \\ Universidade Federal do Rio Grande do Sul - UFRGS/RS, Brasil \\ E-mail: clovisdmassa@gmail.com
}

Revista Cena, Porto Alegre, n. 34, p. 1-187, maio/ago. 2021. 
Este Dossiê da Revista Cena, periódico científico do Programa de Pós-Graduação em Artes Cênicas da Universidade Federal do Rio Grande do Sul (PPGAC/UFRGS), intitulado Pedagogia(s) das Artes Cênicas, foi proposto com vistas a reunir trabalhos resultantes de práticas e reflexões acerca de aspectos do ensino da Dança e do Teatro, atravessados por diferentes teorias, estéticas, contextos e metodologias.

O desejo de lançar este número temático foi instigado por três motivos principais. O primeiro é a necessidade, ou mesmo a urgência, de promover discussões sobre a Arte e a Educação no Brasil, num momento em que os sérios desafios enfrentados pelos profissionais da Educação e da Arte no Brasil são potencializados pela crise sanitária, econômica e educacional decorrente da pandemia do Covid-19. As desigualdades sociais e o impacto de ações governamentais na desvalorização de profissionais das Artes e da Educação e no desmonte de espaços formais e não formais de ensino e de produção cultural têm, por consequência, a drástica redução, se não o aniquilamento, de possibilidades formativas gratuitas, democráticas e de qualidade à população brasileira.

Sob essa ótica, o Dossiê foi pensado como lugar/momento de compartilhamento de desafios das Artes da Cena em espaços educativos, mas também de debate em torno das possibilidades de existência de práticas e reflexões relacionadas à Dança e ao Teatro em diferentes contextos e espaços de formação e convívio social, norteadas por propósitos investigativos e procedimentos diversos.

O segundo motivo, então, para a elaboração do Dossiê, levou em conta que, em nível nacional, as Instituições Federais de Ensino Superior, em geral, e os Programas de Pós-Graduação, especialmente, têm se mostrado espaços propícios à realização de investigações que, de forma ética e rigorosa, favorecem a inserção e o desenvolvimento crítico e consciente de ações artístico-educacionais em diferentes instâncias da vida social ou comunitária.

Como exemplo, têm-se o volume crescente de pesquisas desenvolvidas no PPGAC/UFRGS, nos seus 14 anos de atividade, desde a criação do Curso de Mestrado, em 2007, passando pela implantação do Curso de Doutorado em 2015, correspondendo a uma quantidade expressiva de Dissertações e Teses $^{1}$ orientadas por propósitos educacionais. A maioria delas concentra-se na Linha de Pesquisa 2, denominada "Linguagem, recepção e conhecimento em Artes Cênicas", que reúne pesquisas sobre elementos da cena e sua recepção, e aspectos da formação e da produção de conhecimento em Artes Cênicas, refletidos na articulação com estudos de outros campos da área, como a Literatura, as Artes Visuais e a Música, e de outras áreas do conhecimento, como a Sociologia, a Psicologia, a Antropologia, a História, a Filosofia e, especialmente, a Pedagogia, numa perspectiva interdisciplinar.

A ampliação de investigações que tratam das Artes Cênicas em relação à Pedagogia, processada nas últimas duas décadas, em instituições de sul a norte do país, mobiliza avanços no debate sobre a temática, evidenciando a necessidade de implementação de políticas públicas de fomento à Arte em instituições formais e não formais de ensino, e abertura de vagas docentes às disciplinas de Dança e de Teatro na Educação Básica.

Por fim, a motivação que objetivou, de fato, a organização do Dossiê Pedagogia(s) das Artes Cênicas, foi a proposta do Editor-Chefe da Revista Cena, professor Clóvis Dias Massa, lançada às professoras Vera Lúcia Bertoni dos Santos, (PGAC/UFRGS) e Josiane Franken Corrêa (Universidade Federal de Pelotas), de realização de uma edição em colaboração.

As duas professoras, que vêm de uma longa e produtiva parceria acadêmica no PPGAC, iniciada a partir da relação de orientação e desdobrada numa Dissertação de Mestrado (CORRÊA, 2012), numa Tese de Doutorado (CORRÊA, 2018), ambas no PPGAC/UFRGS, e em diversos trabalhos publicados em coautoria em periódicos da Área de Artes Cênicas, que as mantém em diálogo. Inaugurando as pesquisas em Artes Cênicas e Educação no PPGAC, a Tese defendida por Cor-

1 Dissertações e Teses do PPGAC/UFRGS estão disponíveis em: https://www.ufrgs.br/ppgac/ ou https://lume.ufrgs.br/handle/10183/1 
rêa (2018), intitulada Nós, professoras de Dança: ensaio documental sobre a docência em Dança no Rio Grande do Sul, representou o Programa no Prêmio Capes de Teses 2019, do Mistério da Educação (Brasil), sendo contemplada com Menção Honrosa. A investigação teve por objetivo mapear a docência em Dança nas escolas públicas estaduais do Rio Grande do Sul (RS), na busca de evidenciar possibilidades, limites e estratégias para o ensino de Dança na educação escolar. Para isso, contou com a colaboração de uma comunidade de prática a/r/tográfica, que produziu o documentário "Nós, professoras de Dança", disponível no YouTube ${ }^{2}$.

As parcerias intelectuais e acadêmicas não acontecem estritamente na feitura de trabalhos científicos, mas nas relações dialógicas cotidianas que permeiam os espaços institucionais, entre uma iniciativa e outra, entre a confiança implícita no convite, e no aceite, nas idas e vindas, consultas e decisões, nas avaliações criteriosas das submissões, na comunicação remota entre os colaboradores, entre telas, mensagens, desejos de "Fique bem" e recomendações de "Se puder, fique em casa", em tempos de pandemia.

A pesquisadora Nadja Hermann (2020, p. 7) propõe um enfrentamento colaborativo do momento vulnerável que vivemos. Para ela,

[...] não se avança na superação da epidemia, sem solidariedade e coesão de esforços. Somos seres vulneráveis e dependentes, encontramo-nos entrelaçados numa rede de interdependência social, que exige cuidados recíprocos. O que parece ser um simples regramento sanitário - fique em casa, evite aglomerações - encerra também um juízo ético. Esse tipo de juízo considera as razões internas e específicas de cada caso que é objeto de decisão, a cultura, os valores, a relação com o outro e tudo aquilo que julgamos ser digno de afeição, que atua sobre nossos desejos, nosso caráter e vinculações pessoais. Assim, a decisão de seguir uma norma sanitária diante de uma poderosa pandemia ultrapassa o nosso eu e nos coloca diante da alteridade, do que posso fazer para ser solidário, de como posso colaborar para não

$2 \mathrm{https}: / / \mathrm{www}$.youtube.com/watch?v=PD3XYQTsixA\&t=5s pôr a vida dos outros em risco. A pandemia exige, por detrás do regramento sanitário, uma resposta ética, que é a solidariedade.

De algum modo, este número diz respeito às redes formadas para a realização e permanência de atos artístico-educacionais de cunho colaborativo que, à luz da teoria, transformam a práxis educativa em ação emancipatória. Ao abordar a Educação como conceito que opera em todos os âmbitos da vida humana, Paulo Freire $(1967 ; 1997)$ afirma que o ato educativo exige uma postura ética diante do mundo, envolve práticas e relações libertadoras que possibilitam a criação da autonomia de forma responsável e crítica.

Dos vinte e um trabalhos selecionados para compor o Dossiê Pedagogias das Artes Cênicas, a maior parte é apresentada na seção Artigos, integrada por dezessete produções textuais nitidamente identificadas à proposta deste número temático da Revista Cena. Os outros quatro títulos que completam o Dossiê são dispostos nas demais seções: um deles na seção Conexões, dois na seção Ensaiose Artigos Extradossiê.

A seção Artigos inicia-se pelos trabaIhos mais diretamente relacionados ao campo da Pedagogia da Dança, e que, sob diversas perspectivas, enfocam aspectos conceituais, estruturais, metodológicos e processuais do ensino e da aprendizagem, compreendendo questões importantes à reflexão sobre a área da Dança na sua intersecção com a área da Educação, considerando propostas desenvolvidas em diferentes âmbitos, contextos e níveis do ensino formal e não formal nessa área de conhecimento e atuação docente.

O texto de abertura do Dossiê, de Márcia Strazzacappa, intitulado Com quantos passos se faz um caminho? Um olhar sobre as metodologias de pesquisa de/em dança do Laborarte/UNICAMP, localiza-se no âmbito da pós-graduação, trazendo uma importante contribuição aos processos de produção do conhecimento em Dança e em Educação, fundada na experiência da autora junto ao grupo de pesquisa Laborarte, ligado à Faculdade de Educação da Universidade de Campinas (SP). Sob a perspectiva da A/R/Tografia, Strazzacappa apresenta 
e analisa três Teses de Doutorado defendidas por artistas-pesquisadoras-docentes entre os anos de 2007 e 2013, sob sua orientação, evidenciando, nos percursos investigativos por elas trilhados, aspectos metodológicos e formativos de pesquisa em Dança.

Os dois trabalhos seguintes, também situados nesse campo intermediário entre a Dança e a Educação, têm em comum o propósito de compartilhar experiências práticas e reflexivas de Dança no âmbito do Ensino Superior, relacionadas a processos de conhecimento e formação profissional voltados à docência.

Denominado Práticas de aprendizagem e metodologias do ensino numa Licenciatura em Dança, o texto apresentado por Maria João Fernandes do Nascimento Alves e Margarida Moura reflete sobre a formação de professores de Dança no contexto da Faculdade de Motricidade Humana da Universidade de Lisboa (Portugal), com foco no trabalho docente desenvolvido pelas autoras na disciplina de Metodologia do Ensino da Dança, unidade curricular do Curso de Licenciatura em Dança da Instituição. A descrição e fundamentação dos aspectos conceituais e metodológicos do trabalho desenvolvido na disciplina evidenciam propostas pedagógicas comprometidas com a consolidação e ampliação de teorias e práticas que culminam na elaboração, implementação e avaliação reflexiva e crítica de projetos de ensino e aprendizagem da Dança pelos estudantes-professores de Dança em processo de formação profissional.

Também relacionado à formação docente de nível superior em Dança, o trabalho denominado "Eram de terra seus corpos... De água seus sonhos": incidências de um processo criativo com a(os) Mbya-Guarani na formação de professoras(es) de dança evidencia possibilidades artísticas e pedagógicas do processo de criação cênica e coreográfica do espetáculo Som e Luz em Corpos (2018), que reúne em seu elenco estudantes indígenas da Aldeia Guarani Tekoá Koenjú e licenciandos em Dança da Universidade Federal de Santa Maria (RS). A partir de estudos referenciais acerca da Ecologia de Saberes, das Epistemologias do Sul e da Pedagogia da Autonomia, os pesquisadores Crystian Danny da Silva Castro, Mônica Corrêa de Borba Barboza e Odailso Sinvaldo Berté refletem sobre o processo vivenciado pelos participantes do espetáculo, compreendendo-o como experiência propícia ao diálogo entre epistemologias, culturas e saberes diversos e como oportunidade formativa fundamental ao exercício da docência em Artes na contemporaneidade.

As reflexões propostas nos dois artigos seguintes desenvolvem-se no trânsito entre a formação e a prática docentes, na medida em que enfocam a docência em Dança na Educação Básica em constante processo. O trabalho intitulado Uma professora-artista em cena: vivências que mobilizam o pensar na/sobre docência em Dança na Educação Básica, de Carolina Pinto da Silva e Josiane Franken Corrêa, estabelece diálogo com teorias contemporâneas relacionadas ao ensino da Dança no meio escolar, problematiza aspectos do processo de (auto)formação docente e reflete sobre a noção de professora-artista, compreendendo as diversas funções e deslocamentos da figura da professora como motivadores de propostas de ensino e aprendizagem da Dança voltadas a crianças e jovens em processo de escolarização.

No texto denominado Pequenos brincantes da educação infantil: um encontro entre a dança e as culturas populares brasileiras, apresentado por Fernanda de Souza Almeida e Andreza Lucena Minervino de Sá, o referido trânsito dá-se entre o Ensino Superior e a Educação Infantil, a partir de um trabalho pedagógico realizado em parceria pelo Grupo de Pesquisa em Dança: Arte, Educação e Infância (GPDAEI), constituído por estudantes, docentes e pesquisadores vinculados ao Curso de Licenciatura em Dança da Universidade Federal de Goiás, e duas turmas de crianças e professoras de uma instituição pública de Educação Infantil da cidade de Goiânia (GO). "Fundamentos brincantes, Elementos da dança e Estratégias de abordagem" são os eixos de uma pesquisa-ação mediada por saberes populares, propostas lúdicas, vivências poéticas e reflexões teóricas relacionadas à Dança no contexto educacional.

As relações entre Dança e infância são exploradas também no texto Formação de público especta- 
dor infantil para a dança: reflexões a partir do espetáculo Algodão Doce, de Lidiane Domingues Rodrigues e Helena Thofehrn. O trabalho discute a formação de crianças espectadoras tendo por base ações e reflexões dos participantes do Projeto Algodão Doce (Pelotas, RS), articuladas a estudos teóricos envolvendo a recepção e a criação em Teatro e Dança. Dentre os aspectos considerados favoráveis à formação de espectadores do espetáculo Algodão Doce destaca-se a oportunidade oferecida às crianças, de acesso físico ao teatro, bem como as qualidades artísticas da montagem: os vínculos da encenação com uma estética contemporânea de dança; a ênfase em temáticas relacionadas diretamente ao cotidiano e imaginário infantis; e o caráter lúdico e experimental do processo de criação das cenas, fundado nas possibilidades corporais e improvisacionais do elenco.

A parte da seção Artigos dedicada aos trabaIhos envolvendo a Pedagogia da Dança encerra-se com o texto de Carolina Romano de Andrade, Renata Fernandes dos Santos e Luiza Romani Ferreira Banov, denominado Danças de um tempo: pedagogias da ausência em meio à pandemia. $\mathrm{O}$ trabalho reflete sobre o ensino remoto adotado emergencialmente no contexto educacional em função da necessidade de controle da pandemia do Covid-19, considerando as decorrências do distanciamento das relações interpessoais nos processos de aprendizagem de uma arte presencial como a Dança. "Tempo de escuta", "poética da distância" e "permanência no presente" são as categorias propostas pelas autoras para compreender as especificidades do ensino remoto em Dança no meio escolar e reinventar as relações educativas em tempos pandêmicos.

A parte seguinte da seção Artigos traz os trabalhos relacionados mais diretamente ao campo da Pedagogia do Teatro, a começar por dois textos que enfocam experiências de encenação desenvolvidas no Ensino Superior, compreendidas como atividades formativas ao exercício da docência em Teatro.

Nós ainda brincamos como vocês brincavam? O texto apresentado por Ingrid Dormien Koudela traz no seu título a pergunta que nomeia a encenação teatral resultante do trabalho pedagógico da autora junto às disciplinas de Atuação e Montagem Teatral, oferecidas a estudantes de Licenciatura em Teatro da Universidade de Sorocaba (SP). A obra Children's Plays (Jogos Infantis), do pintor renascentista Pieter Bruegel (1525-1569), é tomada como "modelo de ação" (Brecht) à construção de uma montagem cênica alegórica centralizada no jogo dos atuantes, cujo processo de criação é refletido no texto através de descrições, imagens, depoimentos e teorizações.

Em franco diálogo com os pressupostos teóricos de Koudela acerca do modelo espetacular denominado O espaço no teatro de figuras alegóricas, e também relacionado a experiências investigativas no Curso de Licenciatura da Universidade se Sorocaba (SP), a escrita de As alegóricas, de José Simões de Almeida Junior, parte da retomada de apontamentos e memórias referentes a processos de criação de três montagens cênicas realizadas por estudantes do Curso entre os anos de 2006 e 2008. As experiências propiciadas pelos processos vividos pelos participantes dessas montagens, articuladas a estudos teóricos nos campos das Artes, da Filosofia e da Literatura, dentre outros, dão margem a uma série de discussões, motivando reflexões sobre o espaço, o jogo e a alegoria na criação cênica.

Os textos que se seguem tratam do ensino de Teatro na educação escolar, abrangendo diferentes contextos e níveis do processo de Educação Básica de crianças e jovens, e refletindo sobre experiências teatrais voltadas à aprendizagem de conteúdos específicos da disciplina Arte, oferecida como componente curricular, ou relacionadas a atividades pontuais, de cunho extraclasse, compreendidas sob diferentes perspectivas metodológicas.

No artigo intitulado Teatro no contexto escolar: para uma prática investigativa, experimental e compartilhada, Fernanda Marília Rocha e Vera Lúcia Bertoni dos Santos apresentam reflexões resultantes de uma experiência pedagógica de encenação teatral realizada na disciplina de Arte-Teatro junto a estudantes do Ensino Fundamental de uma escola pública estadual de Porto Alegre (RS). Dentre outros 
aspectos, o texto enfoca as relações entre processo e produto na construção de conhecimento em teatro, o caráter investigativo e experimental da criação cênica e a importância do ensino de teatro na educação escolar na aproximação entre os estudantes e as formas cênicas proliferadas na nossa cultura.

O teatro vai à escola: anotações sobre as primeiras encenações de Aquele Que Diz Sim, de Kurt Weill e Bertolt Brecht para públicos escolares, de Thereza de Jesus Santos Junqueira, propõe-se a compartilhar aspectos do processo de criação dramatúrgica da peça Aquele que diz sim, Aquele que diz não (Brecht e Weill, 1930) particularmente relacionados à aprendizagem do Teatro em âmbito escolar. O referido processo desenvolveu-se a partir da colaboração entre o dramaturgo e um grupo de estudantes do ensino regular e profissionalizante de uma escola de Berlim. As críticas, comentários e propostas dos jovens aprendizes em relação dramaturgia, relacionadas à sua própria condição, motivaram a construção de uma outra versão da peça, constituindo um raro memento de colaboração mútua entre a arte do teatro e a educação.

O trabalho apresentado por Jonas de Lima Sales, intitulado A corponegritude no espaço escolar - um processo cênico-pedagógico, reflete sobre uma experiência investigativa referenciada em saberes de culturas de matriz africana, desenvolvida junto a estudantes do Curso de Artes Cênicas da Universidade de Brasília (DF). O trabalho situa as práticas e reflexões acerca da chamada Corponegritude em relação aos temas transversais, propostos em documentos norteadores da educação brasileira; e apresenta uma proposta pedagógica envolvendo alunos/artistas num trabalho poético e técnico guiado por danças afro-brasileiras.

Desenvolvido no âmbito do Ensino Técnico, o trabalho de Fidelcino Neves Reis, intitulado Processos formativos em teatro musical no Ensino Técnico em Artes Cênicas: um gesto multiperceptivo, parte da própria experiência docente do autor junto a processos de formação em teatro musical, para investigar estratégias metodológicas relacionadas à Educação
Somática, voltadas à preparação corporal e vocal do aluno-ator, à exploração sensorial e à experimentação das múltiplas artes que envolvem o espetáculo.

O texto denominado O professor-narrador: autoridade e responsabilidade como estratégia docente, de Sidmar Silveira Gomes, propõe-se a problematizar discursos relacionados à função do professor de Teatro, em articulação com o debate em torno da Base Nacional Comum Curricular (BNCC), no que se refere às disposições desse documento para o ensino de Teatro na Educação Básica. Em diálogo com teóricos e referências artísticas de campos exteriores à Educação e ao Teatro, o texto reflete sobre a função docente relacionada a aspectos como tradição, autoridade e responsabilidade, compreendidos à figura do "professor-narrador".

Olhares sobre a infância e o teatro: minha formação continuada na Trupe da Alegria é o título do artigo de Diego de Medeiros Pereira, que reflete sobre a sua experiência do autor na coordenação pedagógica de um projeto de formação docente continuada desenvolvido junto à Trupe da Alegria, grupo de teatro integrado por professoras da Educação Infantil, em atividade na cidade de Florianópolis (SC). A narrativa sobre a trajetória artística e investigativa do grupo fundamenta-se em estudos relacionados à Sociologia da Educação, à Psicologia do Desenvolvimento e à Sociologia da Infância, possibilitando uma visão privilegiada de um processo de conhecimento sobre teatro e infância em permanente transformação.

Em Jogo, curiosidade e ad-miração: indícios de aproximação entre a Pedagogia da Autonomia freireana e a Pedagogia do Teatro, Henrique Bezerra de Souza propõem uma aproximação entre a noção de autonomia, de Paulo Freire, e a prática do jogo, compreendida em diversas teorias e abordagens metodológicas relacionadas ao processo de construção de conhecimento em teatro. As descrições e análises de alguns pressupostos e procedimentos do sistema dos jogos teatrais de Viola Spolin, articuladas ao pensamento freireano, ilustram aspectos fundamentais do processo de ensino e aprendizagem do teatro, relacionados à intencio- 
nalidade das ações docentes na condução, avaliação e reflexão das proposições de sala de aula.

No texto que encerra a seção Artigos, denominado Interlocuções entre La Multiplicación Dramática - Eduardo Pavlovsky - e o Arco-Íris do Desejo - Augusto Boal, os autores Douglas Henrique de Oliveira e Neide das Graças de Souza Bortolini evidenciam relações de proximidade entre as práxis teatrais do argentino Eduardo Pavlovski e do brasileiro Augusto Boal, desenvolvidas no contexto latino-americano do século XX. No diálogo entre as trajetórias e contribuições desses dois artistas referenciais ao campo do Teatro são identificadas similaridades contextuais, políticas, estéticas, educacionais e terapêuticas, evidenciando uma poética teatral de resistência, relacionada a transformações pessoais e sociais engendradas no coletivo.

Compondo a seção Ensaios, o texto Reflexões cotidianas em tempos pandêmicos: sobre educação, democracias e desigualdades sociais, que lições aprenderemos com a pandemia?, de Carla Aparecida Costa, enfoca processos de ensino e aprendizagem desenvolvidos no período letivo de 2020, em ambiente de ensino remoto, instaurado desde a pandemia do Covid-19, compreendendo suas decorrências em três grupos de estudantes pertencentes a realidades educacionais e perfis socioeconômicos distintos entre si.

Em seguida, Camila Damasceno Silva aborda os processos de criação coletivos pelo viés da escrita dramatúrgica, no ensaio Navegando nuvens: notas sobre a prática dramatúrgica e os procedimentos de preparação para a escrita, no qual aponta caminhos possíveis para a prática dramatúrgica que não se limita à criação textual, ao relatar processos e procedimentos experimentados no Núcleo Tumulto! de Investigação Cênica. A autora encontra na imagem de um "campo-nuvem", de André Lepecki, e nas fotografias de Shana e Robert ParkeHarrison, noções para a compreender a natureza das materialidades cênicas que surgem no processo de criação.

Na sequência, o artigo de Carolina Felice Bonfim, Are there things only artists can do? Ar- chiving through a treadmill / Há coisas que só os artistas podem fazer? Arquivar através de uma esteira de correr, compõe a seção Conexões. Nele, a pesquisadora realiza uma análise autorreflexiva do projeto de pesquisa-criação Ninety movements on a Technogym G6508D, cuja linha de trabalho concebe o corpo como arquivo vivo, e que se enquadra numa série que a artista desenvolve desde 2010, pautada no estudo de ações consideradas triviais. O significa arquivar um corpo e como se distingue do arquivamento tradicional de documentos e/ou objetos são os pressupostos de sua abordagem sobre o gesto e o movimento, relacionados ao ato de correr em uma esteira, em vias de sua fragmentação, arquivamento e incorporação.

Encerrando o número 34 do periódico, a seção Artigos Extradossiê apresenta o trabalho de Fabiana Fontana e Thayná Máximo de Almeida, Da escrita ao registro da cena na dramaturgia do espetáculo Quem Tem Boca, Vai a Roma, Quem Tem Sorte, ao Polo Norte, no qual as autoras discutem a expansão do conceito dramaturgia no cenário cultural atual, examinando alguns aspectos da problemática, dentre eles, o que se refere aos registros resultantes do processo de criação, os quais constituem, em parte, fontes de estudo da prática teatral.

Finalmente, cabe ressaltar a quantidade expressiva de trabalhos submetidos a esta edição temática da Revista Cena, que se reflete na extensão do Dossiê Pedagogias das Artes Cênicas. O processo de submissão, seleção e editoração dos textos que o compõem, contou com a colaboração de muitos agentes, internos e externos à UFRGS, autores, pares avaliadores e uma equipe de trabalho integrada por docentes e estudantes bolsistas do Programa de Pós-Graduação em Artes Cênicas da UFRGS. A Revista Cena cumprimenta cada um desses agentes, pelo empenho, agradece o interesse dos seus leitores e deseja uma excelente experiência de reflexão acerca das Pedagogia(s) das Artes Cênicas. 


\section{Referências}

CORRÊA, Josiane Gisela Franken. Dança na escola e a construção do co(rpo) letivo: respingos sobre um processo educativo que dança (dançante que educa?). Dissertação (Mestrado em Artes Cênicas). 2012. Programa de Pós-Graduação em Artes Cênicas da Universidade Federal do Rio Grande do Sul. Porto Alegre: Rio Grande do Sul, 2012.

CORRÊA, Josiane Gisela Franken. Nós, professoras de Dança: ensaio documental sobre a docência em Dança no Rio Grande do Sul. Tese (Doutorado em Artes Cênicas). 2018. Programa de Pós-Graduação em Artes Cênicas da Universidade Federal do Rio Grande do Sul. Porto Alegre: Rio Grande do Sul, 2018.

FREIRE, Paulo. Educação como prática da liberdade. Rio de Janeiro: Paz e Terra, 1967.

FREIRE, Paulo. Pedagogia da autonomia: saberes necessários à prática educativa. Rio de Janeiro: Paz e Terra, 1997.

HERMANN, Nadja. A aprendizagem da dor. Educação \& Realidade. Porto Alegre, v. 45, n. 4, 2020. 